\title{
A survey of cricoid pressure application in a single institution in Ethiopia
}

\author{
Naod Bulti Etanaa* (iD and Kore Menjie Benwu
}

\begin{abstract}
Objective: The aim of this survey is to determine the standard of practice of cricoid pressure application on rapid sequence induction in Ayder comprehensive specialized hospital from April 3 to May 3, 2019.

Results: A total of 30 anesthetists were involved in the study with a response rate of $87 \%$. Ninety percent of the respondents do not mask ventilate during rapid sequence induction and they do aspirate the naso-gastric tube if present. Almost half of the respondents have witnessed regurgitation during application of cricoid pressure and $93 \%$ do not remove the naso-gastric tube before rapid sequence induction. Seventy percent had experienced difficulty of endotracheal intubation during application of cricoid pressure. All of the respondents had less than 10 years of working experience as anesthetist.
\end{abstract}

Keywords: Cricoid pressure, Anesthetists, Practice, Knowledge, Rapid sequence induction

\section{Introduction}

Cricoid pressure was initially described by Sellick as a simple method to protect patients from regurgitation of gastric contents during the time of endotracheal intubation [1]. To practice safe and effective use of this maneuver it requires training and knowledge of the related anatomy, technique of application of cricoid pressure and good information about its associated complication.

As originally described by Selilick, immediately before intravenous induction of anesthesia, while the patient is still awake cricoid pressure is applied lightly $(20 \mathrm{~N}$ or $2 \mathrm{~kg}$ ) by trained assistant. Once the patient has lost consciousness, the force on the cricoid cartilage is increased to $(40 \mathrm{~N}$ or $4 \mathrm{~kg}$ ). Cricoid pressure is released after tracheal intubation is confirmed [2].

Vanner initially staged the amount of force to be applied, based on a cadaver study. He advocated an initial force of $20 \mathrm{~N}$ for awake patients and $30 \mathrm{~N}$ after the loss of consciousness in subjects. Subsequently in 1999 he suggested that the initial force be decreased to $10 \mathrm{~N}$ in awake subjects and then slowly increased to $30 \mathrm{~N}$ as the patient lost consciousness [3].

*Correspondence: nbehabesha@gmail.com

Mekelle University, Mekelle, Tigray Region, Ethiopia
Despite the fact that cricoid pressure has become widely accepted as a standard of practice during anesthesia in the United Kingdom (UK) and United states of America (USA) and many parts of the world, none of the papers confirm the perceived clinical benefits of cricoid pressure in reducing the incidence of aspiration during an emergency rapid sequence induction [4].

Though there continues to be controversy regarding the efficacy of cricoid pressure and its safety, it is still a standard practice of most anesthesiologists. Various studies assessing knowledge e of practitioners regarding cricoid pressure $(\mathrm{CP})$ and the effect of training on them have been done. The uniform conclusion in all these studies was that theoretical knowledge of $\mathrm{CP}$ was poor in all categories of tested people including anesthesiologists. These studies included anesthesiologists in Sweden [5] and anesthetic assistants in the UK. Neither of these studies documented whether cricoid pressure had been taught to them as an independent skill or not.

The aim of this institutional survey is to determine the standard of practice of cricoid pressure application for rapid sequence induction in Ayder comprehensive specialized hospital (ACSH) and forward recommendations based on observed performances. 


\section{Main text}

\section{Method and materials}

This study will be conducted in Ayder comprehensive specialized hospital in Mekelle which is found in southern part of Tigray, Ethiopia. The hospitals' anesthetic service is provided by 34 non-physician anesthetists: of whom 12 had Master of sciences (MSc) in anesthesia and 22 had Bachelor of Science (BSc) in anesthesia. It provides more than 7000 surgical and anesthetic care using 9 operating rooms for 10 specialties and subspecialties including neurosurgery, obstetric surgery and pediatric surgery.

This cross sectional, institutional survey was conducted by a means of self-administered structured questionnaires. After taking oral and written informed consent, volunteers were asked to fill up the questionnaires about their routine practice and knowledge regarding cricoid pressure application. The results were analyzed using SPSS (version 20) after the data was compiled and cleansed. Descriptive statistics result was presented as percentages from total responses. The study was conducted from April 3 to May 3, 2019 at Ayder comprehensive specialized hospital.

\section{Results}

A total of 30 anesthetists were involved in the study with a response rate of $87 \%$. From this, $83 \%$ had applied cricoid pressure for rapid sequence induction more than 50 cases in their working experience's. Most, 93\%, had learned how to apply cricoid pressure on a real patient during their clinical practice from anesthesia instructors and $7 \%$ have learned by reading only (Table 1 ).

We also assessed knowledge of cricoid application. The correct anatomic position of cricoid cartilage was identified by $83 \%$. Hundred percent of the participants replied cricoid pressure is applied to prevent aspiration of stomach contents during induction of anesthesia (Table 2).

The correct response for force applied on the cricoid cartilage during rapid sequence induction in an awa and anesthetized patient was $50 \%$. Thirty percent of the respondents believed increasing the cricoid pressure is the right measure if a patient vomits/regurgitates and only $50 \%$ replied releasing the force and suctioning the oropharynx is the correct measure (Table 2).

Majority, 90\%, of the respondents do not mask ventilate during rapid sequence induction and they do aspirate the naso-gastric tube if present. Half, $43 \%$, of the respondents have witnessed regurgitation during application of cricoid pressure and $93 \%$ do not remove the naso-gastric tube before rapid sequence induction. Seventy percent had experienced difficulty of endotracheal intubation during application of cricoid pressure (Table 3 ).
Table 1 Characteristic of anesthetists working in Ayder comprehensive specialized hospital April 3-May 3, 2019

\begin{tabular}{lll}
\hline Characteristics of participants & $\begin{array}{l}\text { Number } \\
\text { of anesthetists }\end{array}$ & Percentage \\
\hline Year of experience (years) & 13 & 43.3 \\
$<2$ & 10 & 33.3 \\
$2-5$ & 7 & 23.3 \\
$5-10$ & 0 & 0 \\
$>10$ & 30 & 100 \\
Have you ever applied cricoid pressure & - & - \\
Yes & & 13.4 \\
No & 4 & 86.6 \\
Number of cricoid pressure application & 26 & - \\
$<50$ times & - & 93 \\
$>50$ times & 28 & - \\
How did you learn to apply cricoid pressure & \\
Shown on a patient during clinical & 28.7 \\
practice or student attachment & & - \\
By reading only & 2 & \\
By practicing on a model or manikin & - & \\
I have never been taught about it & - & \\
\hline
\end{tabular}

\section{Discussion}

Most studies on practices of anesthesiologists regarding cricoid pressure application show a uniform poor theoretical knowledge among all categories of people and unacceptable variation in performance of the maneuver, which often leaves the patient at risk $[6,7]$.

This survey was conducted to determine the practice of application of cricoid pressure here in ACSH. Very few teaching institutes in our country have models where cricoid pressure application can be practiced to indicate forces that are to be used and those centers do not conduct a practical assessment of performance of CP by anesthetists.

Ninety-three (93) percent of the anesthetists had learned how to apply cricoid pressure on a patient during clinical practice or student attachments which shows very high value than a study done in New Zealand which shows only $53 \%$ were taught on a real patient. In this same study, around $20 \%$ had been taught on a model or mannequin whereas our study shows no one had that experience [8]. The reason for this could be that most of anesthesia schools in Ethiopia do not teach their students in a skills lab about appropriate application of cricoid pressure. As the respondents are graduates from different anesthesia schools in Ethiopia, it tells us that our teaching methods should include skills lab teaching of cricoid pressure application in a model (mannequin).

For the knowledge questions where the anatomic position of cricoid cartilage is and the use, the findings were 
Table 2 Assessment of knowledge on cricoid pressure application in anesthetists working in Ayder comprehensive specialized hospital April 3-May 3, 2019

\begin{tabular}{|c|c|c|}
\hline Knowledge on cricoid pressure & $\begin{array}{l}\text { Number } \\
\text { of anesthetists }\end{array}$ & Percentage \\
\hline \multicolumn{3}{|l|}{ Where does cricoid cartilage lie } \\
\hline In front of the thyroid cartilage & 2 & 6.7 \\
\hline Behind the thyroid cartilage & 2 & 6.7 \\
\hline Below the thyroid cartilage & 25 & 83.3 \\
\hline Behind the esophagus & - & - \\
\hline \multicolumn{3}{|l|}{ Why cricoid pressure is used } \\
\hline $\begin{array}{l}\text { Prevent aspiration of stomach contents } \\
\text { during induction of anesthesia }\end{array}$ & 30 & 100 \\
\hline $\begin{array}{l}\text { Prevent patient breathing during } \\
\text { anesthesia }\end{array}$ & - & - \\
\hline $\begin{array}{l}\text { Prevent patient vomiting during } \\
\text { anesthesia }\end{array}$ & - & - \\
\hline $\begin{array}{l}\text { Prevent gastric gas insufflation during } \\
\text { bag mask ventilation }\end{array}$ & - & - \\
\hline \multicolumn{3}{|l|}{ The correct cricoid pressure in awake patient is } \\
\hline 10 & 15 & 50 \\
\hline 20 & 4 & 13 \\
\hline 30 & - & - \\
\hline 50 & - & - \\
\hline Do not know & 11 & 36.7 \\
\hline \multicolumn{3}{|c|}{ The correct cricoid pressure in anesthetized patient is } \\
\hline 10 & 1 & 3.3 \\
\hline 20 & 8 & 26.7 \\
\hline 30 & 20 & 66.7 \\
\hline 50 & - & - \\
\hline Do not know & 1 & 3.3 \\
\hline \multicolumn{3}{|c|}{$\begin{array}{l}\text { Correct measure if a patient vomits/regurgitate during cricoid pressure } \\
\text { application }\end{array}$} \\
\hline $\begin{array}{l}\text { Maintain the same force and suction } \\
\text { the patient's pharynx }\end{array}$ & 3 & 10 \\
\hline $\begin{array}{l}\text { Increase the force and suction the } \\
\text { patient's pharynx }\end{array}$ & 9 & 30 \\
\hline $\begin{array}{l}\text { Decrease the force and suction the } \\
\text { pharynx }\end{array}$ & 3 & 10 \\
\hline $\begin{array}{l}\text { Release the force and suction the } \\
\text { patient's pharynx }\end{array}$ & 15 & 50 \\
\hline \multicolumn{3}{|l|}{ When to release cricoid pressure } \\
\hline After intubation & - & - \\
\hline After inflation of the cuff & 4 & 13 \\
\hline $\begin{array}{l}\text { After confirmation the position of } \\
\text { endotracheal tube }\end{array}$ & 25 & 83.3 \\
\hline I don't know & 1 & 3.3 \\
\hline
\end{tabular}

$83 \%$ and $100 \%$ respectively. The same result was observed in the study done in New Zealand. This could be because this hospital is a teaching hospital and most of them are instructors. In this study only $67 \%$ of them had correctly answered the correct pressure applied on the cricoid cartilage which is slightly higher result than the study done
Table 3 Assessment of practice of cricoid pressure in anesthetists working in Ayder comprehensive specialized hospital April 3-May 3, 2019

Practice of cricoid pressure Number of anesthetists Percentage

Do you routinely mask ventilate during rapid sequence induction

Yes 3210

No $\quad 27 \quad 90$

Do you aspirate before rapid sequence induction

$\begin{array}{lll}\text { Yes } & 26 & 86.7\end{array}$

No $4=13.3$

Do you remove NGT before rapid sequence induction

$\begin{array}{lcc}\text { Yes } & 2 & 6.7\end{array}$

$\begin{array}{lll}\text { No } & 28 & 93.3\end{array}$

Have you witnessed regurgitation during application of cricoid pressure

Yes $13 \quad 43.3$

Have you experienced difficulty to intubate during application of cricoid pressure

Yes $21 \quad 70$

No $\quad 90$

Who applies cricoid pressure when you intubate

Anesthetist $\quad 15 \quad 50$

Anesthesia assistant $\quad 8 \quad 26.7$

$\begin{array}{lll}\text { Nurses } & 5 & 16.7\end{array}$

$\begin{array}{lll}\text { Others } & 2 & 6.7\end{array}$

by Korula $\mathrm{G}$ which was $27 \%$ [9]. This discrepancy could be because of the small sample we have used and the result could be falsely inflated.

In 1983 a study conducted on operating theatre personnel in UK and the USA showed that 70\% had experienced a problem with the application of cricoid pressure which exposed the patient to risks of regurgitation. Ten percent had witnessed regurgitation in that group [7]. This contrasts with our finding where $57 \%$ had experienced regurgitation during rapid sequence induction. The reason for this staggering result could be explained from many perspectives. Many, 33\%, did not identify the correct forces used in the application of cricoid pressure. Problems associated with distorted airway i.e. difficult laryngoscope placement, pharyngeal compression, and laryngeal distortion. It has been seen that incremental cricoid forces when applied on awake subjects lead to difficulty in breathing in half of them [10].

Endoscopic studies assessing the effect of cricoid pressure on the cricoid cartilage and vocal cords show that at forces of up to $44 \mathrm{~N}$ cause difficulty in ventilation was present in $50 \%$ of subjects and vocal cord closure occurred in $60 \%$. Failure of ventilation was lower at $20 \mathrm{~N}$ than at $44 \mathrm{~N}$ [11]. This explains for the reason why $70 \%$ of 
the participants in this study had experienced difficulty of intubation which again is a higher result than the study done in India which was 55\% [9]. This could be because in our study only $76 \%$ of the participants had anesthetist or anesthesia assistants to apply cricoid pressure for them, however, in the previous study it was around $90 \%$.

Training makes a difference in the proper application of cricoid pressure in full stomach patients. A single training session using mannequins has shown to cause marked improvement in performance [5]. The use of simple instructions in an understandable form about the required force and use of simulators for practical training improves performance further $[12,13]$. In addition, inexpensive and simple technique like using $50 \mathrm{ml}$ syringe and depressing the plunger is reliable and linearly related to the force applied between $20 \mathrm{~N}$ and $50 \mathrm{~N}$ as explained by Flucker et al. [14].

\section{Conclusion}

From this study we can learn that significant number of anesthetists had less knowledge of the correct force needed to apply on the cricoid cartilage, witnessed regurgitation of stomach content and majority had experienced difficulty of intubation while cricoid pressure was maintained. Use of simple model for training in higher academic institutions or training in refresher courses for individuals participating in cricoid pressure application in addition to theoretical base may improve the quality of good performance of cricoid pressure application.

\section{Limitations}

To better identify weather the anesthetist's new anatomy of cricoid cartilage and apply the appropriate force, it would have been better if we had had used anatomical model which shows the exact practice. Also, we had small sample size which makes it difficult to generalize to the whole anesthetist working in Ethiopia.

\section{Abbreviations \\ ACSH: Ayder comprehensive specialized hospital; BSc: Bachelor of Science; CP: cricoid pressure; MSc: Master of Science; UK: United Kingdom; USA: United States of America.}

\section{Acknowledgements}

Not applicable.

\section{Authors' contributions}

NBE: made substantial contributions to conception and design, or acquisition of data, or analysis and interpretation of data. KMB: participated in literature review and agreed to be accountable for all aspects of the work in ensuring that questions related to the accuracy or integrity of any part of the work are appropriately investigated and resolved. Both authors revised the manuscript. Both authors read and approved the final manuscript.
Funding

This study was not funded by anyone.

\section{Availability of data and materials}

The data sets generated during and/or analyzed during the current study are not publicly available but are available from the corresponding author on reasonable request.

\section{Ethics approval and consent to participate}

Ethical clearance was obtained from Mekelle university college of health sciences, department of anesthesia, ethical review committee. The committee approved the research and written permission was obtained from Ayder comprehensive specialized hospital medical director to conduct the research. The notification code number given to the title was ERC-CHS/028/ Anst-18/04/19. An informed oral and written consent was obtained from the participants. No participant identifiers were used so as to protect the participants confidentiality.

\section{Consent for publication}

Not applicable.

\section{Competing interests}

The authors declare that they have no competing interests.

Received: 4 July 2019 Accepted: 21 August 2019

Published online: 28 August 2019

\section{References}

1. Sellick BA. Cricoid pressure to control regurgitation of stomach contents during induction of anesthesia. Lancet. 1961;2:404-6.

2. Journal SE. A survey on cricoid pressure application by anesthetists. 2007;8(3):120-6.

3. Vanner RG, Asai T. Safe use of cricoid pressure. Anaesthesia. 1999;54:1-3.

4. Butler J. Cricoid pressure in emergency rapid sequence induction. Emerg Med J. 2005;22:813-6.

5. Vanner RG, Pryle BJ. Regurgitation and esophageal rupture with cricoid pressure: a cadaver study. Anaesthesia. 1992;47:7325.

6. Schmidt A, Akeson J. Practice and knowledge of cricoid pressure in southern Sweden. Acta Anaesthesiol Scand. 2001;45:1210-4.

7. Howells TH, Chamney AR, Wraight WJ, Simons RS. The application of cricoid pressure An assessment and a survey of its practice. Anaesthesia. 1983;38:457-60.

8. Quigley P, Jeffrey P. Cricoid pressure: assessment of performance and effect of training in emergency department staff. Emerg Med Australas. 2007;19(3):218-22.

9. Kirshnan BS, et al. Cricoid pressure: a survey of its practice in India. Indian J Anaesth Clin Investig. 2007;51 (6):505-9.

10. Vanner RG. Tolerance of cricoid pressure by conscious volunteers. Int J Obstet Anesth. 1992;1:195-8.

11. Mac GPJH, Ball DR. The effect of cricoid pressure on the cricoid cartilage and vocal cords: an endoscopic study in anaesthetized patients. Anaesthesia. 2000;55:263-8.

12. Meek T, Gittins N, Duggan JE. Cricoid pressure: knowledge and performance amongst anaesthetic assistants. Anaesthesia. 1999;54:59-62.

13. Ashurst N, Rout CC, Rocke DA, Gouws E. Use of a mechanical simulator for training in applying cricoid pressure. Br J Anaesth. 1996;77:468-72.

14. Flucker CJR, Hart E, Weisz M, Griffiths R, Ruth M. The 50-millilitre syringe as an inexpensive training aid in the application of cricoid pressure. Eur J Anaesthesiol. 2000;17(7):443-7.

\section{Publisher's Note}

Springer Nature remains neutral with regard to jurisdictional claims in published maps and institutional affiliations. 